\title{
QUALIDADE DE QUEIJOS MINAS FRESCAL PRODUZIDOS E COMERCIALIZADOS INFORMALMENTE EM AGROINDÚSTRIAS FAMILIARES
}

\author{
Mariana Barboza Vinha, Cláudia Lúcia de Oliveira Pinto, Maria Cristina Dantas Vanetti, Maria Regina de \\ Miranda Souza, José Benício Paes Chaves
}

\begin{abstract}
RESUMO - Nesta pesquisa relacionaram-se as condições de produção e de comercialização de queijos Minas Frescal produzidos em agroindústrias familiares informais do Município de Viçosa, MG, com a qualidade higiênicosanitária do produto. Foram coletadas $77(38+39)$ amostras de queijos Minas Frescal provenientes de agroindústrias familiares $=$ não inspecionadas. As amostras foram coletadas na fonte de produção e em seus respectivos pontos de comercialização. As condições de produção e de comercialização também foram avaliadas. As agroindústrias apresentaram baixo grau de adequação às Boas Práticas de Fabricação (BPF) e alto percentual de amostras em desacordo com os padrões microbiológicos, o que indica relação direta entre grau de atendimento aos requisitos de BPF e a qualidade do produto final. A qualidade higiênico-sanitária dos queijos foi insatisfatória associada ao alto índice de contaminação por bactérias do grupo coliformes e por estafilococos coagulase positiva. Detectouse a presença de Listeria monocytogenes em uma amostra de queijo. A presença de Salmonella sp não foi constatada em nenhuma das amostras. A adoção de medidas orientativas, o cumprimento das BPF e a melhoria das condições de comercialização do produto são medidas necessárias para aperfeiçoar a qualidade dos queijos produzidos, prevenir a ocorrência de doenças associadas ao consumo de queijos contaminados, reduzir as perdas econômicas de modo a garantir a continuidade da atividade em pequenas agroindústrias familiares.
\end{abstract}

Palavras-chaves: higienização; inspeção, legislação, pasteurização e patógenos.

\section{QUALITY OF MINES FRESCAL CHEESE PRODUCED AND MARKETED INFORMALLY IN FAMILY AGROINDUSTRIES}

\begin{abstract}
This research related conditions of production and commercialization of Minas Fresh cheese produced by not inspected family agribusinesses in the Viçosa, MG, and regarding hygienic-sanitary quality of this product. _77 samples of Minas Frescal cheese were collected in family agroindustries not inspected and their respective retail outlets. During the collection of the samples were evaluated the conditions of production and commercialization cheeses. Agroindustriestring had low degree of adequacy with Good Manufacturing Practices (GMP) and high percentage of cheese samples out the microbiological standards, indicating a direct relationship between the degree of compliance with GMP and quality of final product.
\end{abstract}

Keywords: legislation and inspection, sanitation, pasteurization.

\footnotetext{
${ }^{1}$ Pesquisadora na Empresa de Pesquisa Agropecuária de Minas Gerais - EPAMIG

${ }^{2}$ The sanitary conditions of cheeses analyzed were unsatisfactory due to high contamination by coliforms and coagulase positive staphylococci. Was detected the presence of Listeria monocytogenes in a sample and Salmonella sp was not detected. The adoption of orientative measures, adoption of GMP and the improvement of commercialization conditions are necessary to improve the quality of cheeses produced, prevent the occurrence of illnesses associated with consumption of cheese, reduce economic losses and ensure continuity of activity in small family agroindustries .
} 


\section{INTRODUÇÃO}

O processamento de alimentos em pequenas agroindústrias familiares tornou-se uma alternativa de emprego e renda para as famílias do meio rural, o que possibilitou o desenvolvimento regional e melhoria da qualidade de vida. Estas mudanças contribuíram para redução do número de famílias que deixaram o campo em busca de melhores oportunidades nas cidades (Giraldello et al., 2013). A fabricação do queijo Minas Frescal em pequenas queijarias localizadas em propriedades rurais é muito comum em todo país. Esta popularidade é atribuída à tecnologia simples, ao bom rendimento, à popularização do consumo e à comercialização a preços acessíveis tornando esta atividade rentável para pequenos produtores (Lopes et al., 2006).

O queijo Minas Frescal apresenta alta susceptibilidade a contaminações microbianas, que podem ocorrer a partir do leite usado como matériaprima ou por contaminações durante e /ou após o processamento, especialmente quando produzidos de forma artesanal (Rocha et al., 2006, Zegarra et al., 2009). Estudos indicam baixa qualidade microbiológica de queijos Minas Frescal produzidos em pequenas agroindústrias não inspecionadas (Komatsu et al., 2010; Pinto et al., 2011, Senger \& Bizani, 2011, Amorim et al., 2014, Valiatti et al., 2015, Dias et al., 2016). A regularização sanitária desses estabelecimentos contribui para a melhoria dos padrões microbiológicos dos produtos fabricados de modo a reduzir os riscos para a saúde pública e possibilita a inserção do produto no mercado formal facilitando sua comercialização e garantindo a continuidade da atividade (Lombardi \& Correio, 2014).

O leite cru pode veicular diversos microrganismos patogênicos (Zegarra et al., 2009), no entanto, sua utilização é uma prática comum na fabricação de queijos frescos artesanais produzidos em estabelecimentos não inspecionados (Moraes et al., 2009; Almeida et al., 2012; Garcia et al., 2016). A pasteurização do leite para fabricação de derivados tem como objetivo inativar os patógenos provenientes da matéria-prima. Após a pasteurização não há outra etapa no processo de fabricação de queijos frescos capaz de eliminar ou reduzir o crescimento de microrganismos, portanto torna-se imprescindível a adoção de boas praticas de fabricação para evitar a recontaminação ou contaminações cruzadas e garantir a segurança do produto. O uso de matériaprima insegura associada às condições higiênicosanitárias de fabricação e comercialização_contribui para tornar os queijos frescos produzidos com leite cru um produto de alto risco para saúde do consumidor (Zegarra et al., 2009; Almeida et al., 2012; Torres-Vitela et al., 2012).

Surtos relacionados a doenças de origem alimentar decorrente do consumo de queijos, especialmente fabricados a partir de leite cru resultaram em um maior número de hospitalizações e foram atribuídos ao consumo de queijos fabricados ou comercializados de forma ilegal nos Estados Unidos (Gould et al., 2014).-No Brasil, surtos envolvendo o consumo de queijos, especialmente os de fabricação caseira, ocorreram no Estado de Minas Gerais As principais causas desses surtos foram o uso de leite cru na fabricação de queijos, a pasteurização ineficiente, o uso de leite proveniente de animais com mastite, as contaminações cruzadas, as falhas no monitoramento da produção e a ineficiência dos procedimentos de higienização (Carmo et al., 2002, Perry, 2004). A adoção das boas práticas agropecuárias e de fabricação é fundamental para produção de queijos em conformidade com os padrões de qualidade sanitária (Almeida et al., 2012, Souza et al., 2014). Produtores e comerciantes devem compreender a importância da regularização sanitária das pequenas queijarias familiares e do cumprimento dos requisitos de boas práticas, bem como da responsabilidade de oferecer um produto seguro ao consumidor (Lombardi \& Correio 2014).

Objetivou-se relacionar aspectos de adequação sanitária da fabricação e de comercialização do queijo Minas Frescal produzido por agroindústrias familiares não inspecionadas com a qualidade higiênico-sanitária do produto, avaliada com base nos padrões microbiológicos estabelecidos pela legislação.

\section{MATERIAL E MÉTODOS}

O estudo foi conduzido em seis agroindústrias familiares não inspecionadas, localizadas em comunidades rurais do município de Viçosa-MG. Em três agroindústrias produziam-se queijos com leite pasteurizado e, em outras três, a partir de leite cru. Para cada agroindústria selecionada foram avaliadas as condições de fabricação e as condições de comercialização em pontos de venda informados pelos produtores. Foram coletadas amostras de queijo nas 
agroindústrias e nos seus respectivos pontos de venda para realização de análises microbiológicas. Foram planejadas duas coletas de amostras por estação do ano em cada uma das seis agroindústrias, entretanto, no período da seca houve interrupção da atividade em algumas agroindústrias em função da escassez de matéria-prima. Desta forma, foram coletadas 39 amostras de queijos na fonte de produção dentre as 48 planejadas. Para amostragem nos pontos de venda seguiu-se o mesmo planejamento, duas coletas a cada estação do ano, nas quatro estações. Os pontos de venda foram selecionados aleatoriamente. A coleta das amostras foi realizada, no mínimo 24 horas e, no máximo, sete dias após a entrega do produto no comércio. Foram coletadas 38 amostras em pontos de venda das 48 planejadas.

A avaliação das condições sanitárias de produção foi realizada por meio de observação e entrevista direcionada por uma lista de verificação elaborada com base na Resolução - RDC n 275 , de 21 de outubro de 2002. Foram avaliados 37 itens de boas práticas, para cada item de boas práticas foi atribuída uma pontuação em escala de zero a dez, sendo zero a pior e dez a melhor situação. Os itens classificados como não aplicáveis foram excluídos do número total de itens para obtenção da nota final do estabelecimento. A pontuação ponderada foi obtida para cada agroindústria e, com base nesta pontuação, suas condições de processamento foram classificadas como "ruim" quando obtiveram pontuação entre $0 \%$ e $50 \%$, "regular" com pontuação entre $51 \%$ e $75 \%$ e "boa" com pontuação entre $76 \%$ e $100 \%$.

As condições sanitárias de comercialização foram avaliadas por meio de observação direcionada com a aplicação da lista de verificação, previamente elaborada com base nas exigências do Serviço de Vigilância Sanitária para comercialização de produtos de origem animal. A lista era composta por perguntas discursivas e objetivas. As perguntas objetivas foram computadas como um ponto para respostas positivas e zero para respostas negativas, questões não aplicáveis ao estabelecimento foram excluídas da contagem total. As respostas das questões discursivas foram agrupadas para calcular o percentual de respostas iguais. As questões foram agrupadas em seis blocos: tipo de estabelecimento; embalagem, rotulagem, condições de estocagem, irregularidades observadas e manipulador. A temperatura do equipamento utilizado para armazenamento dos queijos no estabelecimento foi verificada no momento da coleta das amostras com auxílio de termômetro digital. As condições de comercialização foram avaliadas durante a coleta das amostras.

Para as análises microbiológicas dos queijos utilizou-se a metodologia oficial (Brasil, 2003). As amostras foram submetidas às análises microbiológicas exigidas pela $\mathrm{RDC} \mathrm{n}^{\circ} 12$, de 2 de janeiro de 2001 do Ministério da Saúde e Portaria no 146 de 07 de março de 1996 do Ministério da Agricultura. Os resultados das análises foram comparados com os padrões exigidos pelo Ministério da Agricultura para amostras coletadas na fonte de produção (Brasil 1996). Os resultados das amostras coletadas nos pontos de venda foram comparados com os padrões da Agência Nacional de Vigilância Sanitária (Brasil 2001), para amostras indicativas de lote. A qualidade higiênico-sanitária do produto foi associada com aspectos de adequação técnica e estrutural de produção e de comercialização avaliados. Os resultados das avaliações foram agrupados e descritos na forma gráficos e tabelas.

\section{RESULTADOS E DISCUSSÃO}

A maior parte das agroindústrias, cinco das seis estudadas, não possuía local exclusivo para a fabricação e utilizavam a própria cozinha da residência para produzir os queijos. Constatou-se também a ausência dos procedimentos padrão para higienização das instalações conforme as determinações de Brasil 2002. Essas práticas favorecem a contaminação cruzada em função da manipulação inadequada do produto e de outros alimentos o que pode colocar em risco a inocuidade e a qualidade dos queijos produzidos.

O uso de leite cru como matéria-prima foi uma irregularidade observada em três das seis agroindústrias estudadas e pode ser atribuída ao desconhecimento da importância da pasteurização por parte dos produtores e à tradição cultural de produzir queijo com leite cru. Alguns produtores alegaram que a pasteurização do leite interfere no sabor do produto e na aceitação pelo consumidor.

$O$ percentual de adequação às $B P F$ das agroindústrias foi muito baixo com variação de $28 \%$ a $45 \%$. As condições de produção em todos os estabelecimentos foram classificadas como "ruim" (Tabela 1). A agroindústria codificada como PSS2 apresentou maior percentual de adequação e era a única que dispunha 
Tabela 1 - Atendimento aos requisitos de Boas Práticas de Fabricação e classificação das agroindústrias familiares produtoras de queijos Minas Frescal não inspecionadas do Município de Viçosa, MG

\begin{tabular}{|c|c|c|c|c|c|c|c|}
\hline \multirow{2}{*}{ Requisitos } & \multicolumn{6}{|c|}{ Produtores } & \multirow{2}{*}{ Média } \\
\hline & PSS1 & PSS2 & PSS3 & PSS4 & PSS5 & PSS6 & \\
\hline Classificação dos empreendimentos & Ruim & Ruim & Ruim & Ruim & Ruim & Ruim & Ruim \\
\hline Requisitos gerais & 33 & 45 & 42 & 32 & 43 & 28 & 37 \\
\hline Edificação e Instalações & 45 & 45 & 47 & 38 & 51 & 38 & 44 \\
\hline Controle Integrado de Pragas & 0 & 50 & 0 & 0 & 0 & 0 & 8 \\
\hline Abastecimento de água & 27 & 44 & 41 & 34 & 44 & 34 & 37 \\
\hline Manejo dos resíduos & 57 & 47 & 82 & 70 & 85 & 55 & 66 \\
\hline Equipamentos, móveis e utensílios & 44 & 56 & 56 & 36 & 48 & 32 & 45 \\
\hline Manipuladores & 23 & 30 & 30 & 22 & 30 & 21 & 26 \\
\hline Produção e transporte & 35 & 44 & 41 & 30 & 44 & 28 & 37 \\
\hline Higienização & 39 & 40 & 49 & 34 & 54 & 29 & 41 \\
\hline
\end{tabular}

de local independente para fabricação dos queijos, mas, utilizava leite cru como matéria-prima. A agroindústria codificada como PSS6 obteve o pior resultado, fabricava os produtos na varanda da casa, em condições precárias de higiene e usava leite cru como matéria-prima. Nenhuma agroindústria apresentou documentação referente às boas práticas e ao controle de qualidade do produto final. O manejo de resíduos foi o requisito que apresentou maior percentual de atendimento, entre $55 \%$ a $85 \%$, com média de $66 \%$. Os demais itens apresentaram média do percentual de adequação inferior a 50\%, o que reforça o baixo grau de adequação aos requisitos legais de boas práticas. Os blocos controle integrado de pragas, e higiene e saúde dos manipuladores, abastecimento de água e produção e transporte apresentaram menores percentuais médios de adequação conforme Tabela 1 .

A ausência de infraestrutura é a principal dificuldade apresentada pelas agroindústrias para regularização do estabelecimento e os produtores relataram dificuldades financeiras e dificuldade de obtenção de crédito para realização do investimento. Outros desconhecem a relevância das adequações para garantir a segurança do produto. Resultado semelhante foi observado por Vicentini et al. (2013) que identificaram baixo percentual de adequação em pequenos estabelecimentos produtores de queijo em Minas Gerais. Segundo os produtores, a dificuldade de regularização dos empreendimentos é relacionada ao alto grau de exigência por parte do órgão fiscalizador e ao custo envolvido na adequação dos estabelecimentos às essas exigências (Miyaji \& Soares, 2002; Vicentini et al., 2013). No entanto, a flexibilização das normas e padrões de qualidade pleiteada por esses produtores pode colocar em risco a inocuidade dos produtos e a saúde pública caso não haja uma análise crítica do impacto desses ajustes solicitados na segurança dos produtos fabricados.

O principal ponto de venda de queijos produzidos na informalidade era a feira livre $(45 \%)$. Muitos proprietários de açougues, padarias e mercados evitam a comercialização desses queijos com receio de punições por parte da vigilância sanitária municipal. Mesmo sob o risco de punições, alguns proprietários de açougues e mercearias, principalmente em comunidades rurais, ainda comercializavam o produto produzido na informalidade, uma vez que $30 \%$ das amostras foram coletadas em mercados e mercearias, $14 \%$ em açougues e $14 \%$ em hortifrutis. Constatou-se que $79 \%$ dos queijos eram mantidos em condições de refrigeração durante a comercialização e, $21 \%$ eram comercializadas em caixas térmicas, sendo que apenas $1 \%$ dessas caixas continha gelo. A maior parte das amostras coletadas estava acondicionada a temperaturas superiores $(51 \%)$ ou iguais $(5 \%)$ a $10^{\circ} \mathrm{C}$. Uma quantidade considerável de amostras $(43 \%)$ era armazenada a temperaturas inferiores da $10^{\circ} \mathrm{C}$. Esses resultados são semelhantes aos de outros estudos em que a falta de controle da temperatura durante a comercialização de queijos e outros lácteos foi constatada (Ferreira et al., 2010; Dias et al., 2016; Fonseca et al., 2016). Produtos lácteos armazenados sob temperaturas inadequadas contribuem para tornar o produto inseguro e podem ocasionar problemas de saúde pública em virtude da possibilidade de ocorrência de surtos e casos de doenças veiculadas por este tipo de produto. A manutenção do produto a temperaturas inferiores a $10^{\circ} \mathrm{C}$ é uma medida importante para fins de prevenção 
da produção de toxinas termoestáveis e redução da velocidade de multiplicação de alguns patógenos. $\mathrm{O}$ risco à saúde pública é agravado quando se trata da fabricação de queijos com leite cru, uma vez que esta matéria-prima pode estar contaminada com patógenos sensíveis à pasteurização do leite. Constatou-se que 97\% das amostras coletadas estavam em condições inadequadas de conservação nos pontos de comercialização. As irregularidades observadas com maior frequência foram: acondicionamento concomitante com outros tipos de produtos (47\%), higienização insuficiente dos balcões ou caixas térmicas (20\%) e focos de contaminações visíveis (7\%) (Tabela 2).

Irregularidades na comercialização de produtos lácteos foram relatadas em outros estudos (Ferreira et al., 2010, Araújo et al., 2014). As falhas detectadas durante a comercialização ocasionam contaminação microbiana dos produtos que comprometem sua inocuidade e qualidade e resulta em risco à saúde do consumidor, problemas de saúde pública e perdas econômicas para as empresas.

A qualidade microbiológica dos queijos analisados foi insatisfatória com alto percentual de amostras em desacordo com o padrão estabelecido para de queijos coletados nas agroindústrias e no comércio (Tabela 3 ). Alto percentual de amostras em desacordo com os padrões legais também foram constatados por outros autores (Ferreira et al., 2010; Komatsu et al., 2010; Martins \& Reis; 2012; Dias et al., 2016, Garcia et al., 2016). Resultados diferentes foram observados ao analisarem queijos fabricados com leite pasteurizados sob inspeção do serviço federal (Zocche et al., 2012, Lombardi \& Correio, 2014; Souza et al., 2014) o que aponta para uma maior segurança deste tipo de produto.
As amostras coletadas no comércio apresentaram número mais provável (NMP/g) de coliformes a $30^{\circ} \mathrm{C}$ (totais) e coliformes a $45^{\circ} \mathrm{C}$ (termotolerantes) maior quando comparado aos resultados de amostras coletadas na agroindústria. Apenas um produtor, PSS4, apresentou melhor resultado para coliformes a $45^{\circ} \mathrm{C}$ para amostras coletadas no comércio, resultado que pode ser justificado por se tratar de amostras de lotes independentes (Tabela 3). A alta contaminação por coliformes totais nos queijos reflete a falta de higiene no processamento e na manipulação. O elevado número de amostras em desacordo ao padrão estabelecido para coliformes termotolerantes é um indicativo da presença de microrganismos patogênicos como a Escherichia coli. Os coliformes termotolerantes pertencem a um grupo de microrganismos que tem habitat no trato intestinal do homem e outros animais, desta forma a presença desses microrganismos no alimento indica contaminação fecal do produto, o que torna o consumo deste tipo de queijo um risco para a saúde dos consumidores (Apolinário et al., 2014; Garcia et al, 2016).

Amostras de queijo Minas Frescal produzidos com leite pasteurizado apresentaram melhores resultados para coliformes a $45^{\circ} \mathrm{C}$ comparados as amostras de queijos produzidos com leite cru, o que reforça a indispensabilidade da pasteurização para reduzir a contaminação por esse grupo de bactérias e para obtenção de produtos de acordo com os padrões higiênico-sanitários (Tabela $\underline{3} 4$ ). A ocorrência de coliformes totais e termotolerantes em limites acima ao estabelecidos pela legislação (Brasil 1996, Brasil 2001) em amostras de queijos produzida com leite pasteurizado podem estar relacionadas à falha no processo de pasteurização ou à contaminação ocorrida

Tabela 2 - Percentual de irregularidades observadas nos estabelecimentos comerciais durante a coleta das amostras de queijos Minas Frescal provenientes de agroindústrias não inspecionadas do município de Viçosa, MG

\begin{tabular}{lcc}
\hline \multicolumn{1}{c}{ Tipo de irregularidades } & Número de Ocorrências & Frequência \\
\hline Armazenamento concomitante com outros produtos & 41 & $47 \%$ \\
Limpeza dos balcões insuficiente & 17 & $20 \%$ \\
Focos de contaminação visíveis & 8 & $9 \%$ \\
Recipiente de acondicionamento inadequado & 7 & $8 \%$ \\
Acúmulo de gelo nos balcões & 3 & $3 \%$ \\
Falta de organização & 2 & $2 \%$ \\
Mistura com outros queijos sem rótulo & 1 & $1 \%$ \\
Empilhamento excessivo & 1 & $1 \%$ \\
Estado de conservação dos equipamentos de exposição & 87 & $100 \%$ \\
Total de ocorrências & & $3 \%$ \\
\end{tabular}


Tabela 3 - Percentual de amostras em desacordo com os padrões microbiológicos provenientes agroindústrias familiares não inspecionadas do município de Viçosa, MG

\begin{tabular}{|c|c|c|c|c|c|c|}
\hline \multicolumn{2}{|c|}{ Procedência da amostras } & \multirow{2}{*}{$\begin{array}{c}\text { Tipo de } \\
\text { matéria-prima }\end{array}$} & \multirow{2}{*}{$\begin{array}{c}\begin{array}{c}\text { Amostras em } \\
\text { desacordo }(\%)\end{array} \\
75\end{array}$} & \multirow{2}{*}{$\begin{array}{c}\begin{array}{c}\text { Coliformes a } \\
30{ }^{\circ} \mathrm{C}^{*}(\%)\end{array} \\
75\end{array}$} & \multirow{2}{*}{$\begin{array}{c}\begin{array}{c}\text { Coliformes } \\
\text { a } 45{ }^{\circ} \mathrm{C}(\%)\end{array} \\
25\end{array}$} & \multirow{2}{*}{$\begin{array}{c}\begin{array}{c}\text { Estafilococos } \\
\text { Coagulase } \\
\text { Positiva }(\%)\end{array} \\
25\end{array}$} \\
\hline Fonte de produção & PSS1 & & & & & \\
\hline & PSS3 & & 100 & 100 & 38 & 0 \\
\hline & PSS5 & & 100 & 88 & 75 & 0 \\
\hline & PSS2 & Leite Cru & 100 & 100 & 100 & 88 \\
\hline & PSS4 & & 100 & 100 & 100 & 75 \\
\hline & PSS6 & & 100 & 100 & 100 & 67 \\
\hline & Total & 95 & 93 & 62 & 33 & \\
\hline \multirow[t]{7}{*}{ Comércio } & PSS1 & Leite pasteurizado & 100 & 100 & 25 & 13 \\
\hline & PSS3 & & 100 & 100 & 25 & 0 \\
\hline & PSS5 & & 100 & 100 & 40 & 0 \\
\hline & PSS2 & Leite Cru & 100 & 100 & 88 & 75 \\
\hline & PSS4 & & 100 & 100 & 43 & 71 \\
\hline & PSS6 & & 100 & 100 & 100 & 50 \\
\hline & Total & 100 & 100 & 56 & 34 & \\
\hline
\end{tabular}

* A legislação (BRASIL, 2001) não estabelece padrão para coliformes a $30^{\circ} \mathrm{C}$ e utilizou-se o padrão recomendado para amostras coletadas na fonte de produção para efeito de comparação.

após a pasteurização em função do não cumprimento dos requisitos de BPF. A ocorrência de contaminações cruzadas durante o processamento foi constatada ao observar a ausência de local exclusivo e apropriado para a produção dos queijos, ausência de barreiras sanitárias e falta do controle de acesso de pessoas alheias à manipulação e pragas, entre outras irregularidades observadas (Tabela 1). Essas irregularidades observadas implicam na contaminação do produto, principalmente após tratamento térmico.

Amostras coletadas no comércio também apresentaram contagem de Estafilococos coagulase positiva superiores às observadas na fonte de produção. Em amostra coletada no comércio, foi constatada contagem de Estafilococos coagulase positiva superior a $10^{6} \mathrm{UFC} / \mathrm{g}$, o que indica a possibilidade do queijo estar contaminado com a toxina estafilocócica. O predomínio de amostras em desacordo com os padrões para Estafilococos coagulase positiva coletadas no comércio pode estar relacionada a falhas de refrigeração, ou até mesmo à falta de refrigeração, constatadas nos pontos de venda (Tabela 2). Este resultado reforça a importância do controle da temperatura de armazenamentos dos queijos nos pontos de venda para minimizar a multiplicação desses microrganismos de modo que a sua população microbiana não atinja contagem suficiente para que ocorra produção de enterotoxinas.
Queijos fabricados com leite cru apresentaram maior percentual de amostras em desacordo com os padrões estabelecidos por Brasil 1996 e Brasil 2001 para estafilococos coagulase positiva. Este grupo de microrganismos pode ser encontrado no leite recémordenhado e indica a ocorrencia de falhas higiênicas durante a ordenha e/ou uso de leite de vacas portadoras de mastite, uma vez que, Staphylococcus aureus é um dos principais causadores dessa infecção (Zegarra, et al., 2009). A pasteurização do leite é a principal alternativa para reduzir a contaminação da matériaprima e eliminar patógenos, portanto o uso de leite cru na fabricação dos queijos representa um grande risco visto. A inativação desse patógeno na matériaprima é imprescindível para a obtenção de produtos aceitáveis isentos de enterotoxinas termoestáveis associadas a gastroenterites. Apenas um dos produtores que produzia queijos a partir de leite pasteurizado apresentou amostras em desacordo com os padrões para estafilococos coagulase. A contaminação das amostras pode ser associada à contaminações pós pasteurização justificadas pelo baixo percentual de adequação às boas práticas e irregularidades observadas durante a manipulação do produto (Tabela 1).

Em nenhuma das amostras foi constatada a presença de Salmonella sp., em $25 \mathrm{~g}$ de amostra, mesmo em queijos fabricados com leite cru, semelhante aos resultados observados por Moraes et al. (2009); Pinto et al. (2011); 
Almeida et al. (2012); Melo et al. (2013); Apolinário et al. (2014); Amorim et al (2014) e Dias et al.(2016). Os resultados diferem dos estudos de Zegarra et al (2009); Torres-Vitela et al. (2012) e Garcia et al., (2016) que detectaram Salmonella sp em queijos frescos. A ausência do patógeno nas amostras pode ser justificada pela baixa capacidade competitiva de Salmonella sp. em relação a bactérias do grupo coliformes e Staphylococcus spp. (Almeida et al., 2012; Melo et al., 2013). A presença de bactérias láticas e bactérias do grupo coliforme contribuem para acidificação no meio, o que torna o ambiente adverso à sobrevivência do patógeno, o que pode resultar na sua inativação em situações que apresentam baixa contaminação inicial. Nestas condições o patógeno pode ser inativado ou permanecer em números indetectáveis em alimentos (Pinto et al. 2011; Melo et al. 2013). Embora constatada ausência de Salmonella sp. nas amostras, o alto grau de contaminação com bactérias indicadoras de contaminação de origem fecal, implica em riscos de infecções associadas a bactérias da família Enterobacteriaceae.

Listeria monocytogenes foi detectada em uma amostra coletada em uma das agroindústrias familiares que utilizava leite pasteurizado para fabricação do queijo. O produto era fabricado na cozinha da residência e não havia um local exclusivo para produção, situação que possibilita a contaminação pós-pasteurização. A pasteurização era realizada, mas, não havia controle do binômio tempo/temperatura o que não garantia a eficácia do tratamento. L. monocytogenes é sensível à pasteurização do leite (FDA, 2012), entretanto, falhas no controle do binômio tempo/temperatura comprometem a eficiência do processo. Estudos similares identificaram presença do patógeno em amostras de queijos inspecionadas e artesanais (TorresVitela et at., 2012; Melo et al., 2013, Apolinario et al., 2014) o que aponta para necessidade de utilizar o leite pasteurizado na produção de queijos e manter condições higiênicas adequadas após o tratamento térmico de modo a prevenir a contaminação cruzada dos produtos. O consumo de produtos lácteos contaminados por L. monocytogenes é uma causa frequente da ocorrência de surtos de listeriose. Este patógeno é responsável por causar a listeriose invasiva e a não invasiva, forma mais branda da doença, em humanos. A listeriose não invasiva caracteriza-se por provocar gastroenterite febril e pode afetar pessoas saudáveis e que não pertencem aos grupos de risco. A listeriose invasiva afeta indivíduos pertencentes a grupos de risco como imunodeprimidos, idosos, neonatos, crianças e mulheres grávidas. Em gestantes o patógeno pode provocar aborto, parto pré-maturo e malformação do feto, além de infecção generalizada no recém-nascido. Em crianças, idosos e imunodeprimidos a bactéria pode atingir o sistema nervoso central, causar meningite ou meningoencefalite e ocasionar óbito (Barancelli et al., 2011).

\section{CONCLUSÃ̃O}

A qualidade higiênico-sanitária dos queijos Minas Frescal produzidos em agroindústrias familiares informais do município de Viçosa/MG é insatisfatória e seu consumo representa risco à saúde do consumidor, em especial, quando utilizado leite cru como matériaprima. A pasteurização do leite, a formalização junto ao Serviço de Inspeção e a implantação das BPF são medidas a serem adotadas para garantir a inocuidade do produto. Medidas educativas devem ser adotadas em toda cadeia produtiva, se estendendo à comercialização, para garantir a segurança do produto oferecido ao consumidor. A elaboração de políticas públicas direcionadas aos pequenos produtores são fatores relevantes para garantir a sustentabilidade da produção artesanal de queijos.

\section{AGRADECIMENTOS}

À Fundação de Amparo à Pesquisa do Estado de Minas Gerais (FAPEMIG) e ao Conselho Nacional de Desenvolvimento Científico e Tecnológico (CNPq) pelo apoio financeiro.

\section{LITERATURA CITADA}

ALMEIDA, A.C; DINIZ, T.T.; SOUZA, M.R.; PINTO, M.S.; SOUZA, R.M.; SILVA, N.O.; QUEIROZ, M.R.A. Caracterização da produção de queijo artesanal na região de Montes Claros, norte de Minas Gerais. Acta Veterinaria Brasilica, v.6, n.4, p.312-320, 2012.

AMORIM, A.-L.-B.-C.; COUTO, E.-P.; SANTANA, A.-P.; RIBEIRO, J.-L.; FERREIRA, M.-A. Avaliação da qualidade microbiológica de queijos do tipo Minas padrão de produção industrial, artesanal e informal. Revista do Instituto Adolfo Lutz, v.73, n.4, p.364-7, 2014. 
APOLINÁRIO, T.-C.-C.; SANTOS, G.-S.; LAVORATO, J.-A.-A. Avaliação da qualidade microbiológica do queijo Minas Frescal produzido por laticínios do estado de Minas Gerais.

Revista do Instituto de Laticínios

Cândido Tostes, v. 69, n. 6, p. 433-442, 2014.

ARAÚJO, K.-S.-S.; CARVALHO, K.-A.; AZEVEDO, L.-S.; SANTOS, R.-M.; NASCIMENTO, I.-O.; ARAÚJO, M.-M. Avaliação do armazenamento de produtos lácteos comercializados em supermercados de Imperatriz - MA.

Agroecossistemas, v. 6, n. 1, p. 97-102, 2014.

BARANCELLI G.V., SILVA-CRUZ J.V., PORTO E., OLIVEIRA C.A. F. Listeria monocytogenes: ocorrência em produtos lácteos e suas implicações em saúde pública. Arquivo do Instituto de Biologia, v.78, n.1, p.155-168, 2011.

BRASIL. Ministério da Agricultura Pecuária e Abastecimento. Portaria n. 146, de 07 de março de 1996. Regulamentos Técnicos de Identidade e Qualidade dos Produtos Lácteos. Diário Oficial da União, Brasília, DF, Seção 1, p. 3977.

BRASIL. Ministério da Agricultura, Pecuária e Abastecimento. Instrução Normativa n. 62, de 26 de agosto de 2003. Oficializa os Métodos Analíticos Oficiais para Análises Microbiológicas para Controle de Produtos de Origem Animal e Água. Diário Oficial da União, Brasília, DF, 18 set. 2003, Seção 1, p. 14.

BRASIL. Ministério da Saúde. Agência Nacional de Vigilância Sanitária - ANVISA. RDC n. 12, de 02 de janeiro de 2001. Regulamento técnico sobre padrões microbiológicos para alimentos. Diário Oficial da União, Brasília, DF, Seção 1, p. 4553.

BRASIL. Ministério da Saúde. Agência Nacional de Vigilância Sanitária - ANVISA. Resolução $\mathrm{RDC}^{\circ}{ }^{\circ} 275$, de 21 de outubro de 2002. Dispõe sobre o Regulamento Técnico de Procedimentos Operacionais Padronizados aplicados aos Estabelecimentos Produtores/Industrializadores de Alimentos e a Lista de Verificação das Boas Práticas de Fabricação em Estabelecimentos Produtores/Industrializadores de Alimentos. Diário Oficial da União, Brasília, DF, seção 1, p. 126.
CARMO, L.-S.; DIAS, R.-S.; LINARDI, V.-R. Food poisoning due to enterotoxigenic strains of Staphylococcus present in Minas cheese and raw milk in Brazil. Food Microbiology, v. 19, n.1, p. $9-4,2002$.

DIAS, B.-F.; FERREIRA, S.-M.; CARVALHO, V.-S.; SOARES, D. S. B. Qualidade microbiológica e físico-química de queijo Minas Frescal artesanal e industrial. Revista de Agricultura

Neotropical, v. 3, n. 3, p. 57-64, 2016.

FERREIRA, G.-B.; OLIVEIRA, A.-C.-S.; MARSON, J.-M.; TERRA, A.-P.-S. Pesquisa de

Staphylococcus aureus em queijos tipo "Minas Frescal" comercializados na região do triângulo mineiro. Revista Baiana de Saúde Pública, v.34, n.3, p.575-589, 2010.

FONSECA, B.-C.-P da.; REIS, J.-N.; SANTOS, M. $\mathrm{S}$. Avaliação microbiológica de produtos lácteos comercializados na cidade de Vitória da Conquista - Bahia. Revista Saúde.Com, v.12, n.2, p. 575-583, 2016.

FOOD AND DRUG ADMINISTRATION OF THE UNITED NATIONS FDA, 2012. The Dangers of Raw Milk: Unpasteurized Milk Can Pose a Serious Health Risk. Center for Food Safety and Applied Nutrition Food Information. Disponível em: <http://www.fda.gov/ downloads/Food/FoodborneIllnessContaminants/ UCM239493.pdf> Acesso em: 03 de outubro de 2016.

GARCIA, J.-K.-S.; PRATES, R.-P.; FARIAS, P.-K. S. GONÇALVES, S.-F.; SOUZA, C.-N. Qualidade microbiológica de queijos frescos artesanais comercializados na região do norte de Minas Gerais. Caderno de Ciências Agrárias, v. 8, n. 2, p. 58-65, 2016.

GIRALDELLO, F.; STOFFE, J.-A.; LIMA, J.-F.; LAVALL, V.-L. A agroindústria familiar na microrregião de Francisco Beltrão (PR). Revista FAE, v. 16, n. 1, p. 162-177, 2013.

GOULD, L.-H.; MUNGAI, E.; BEHRAVESH, C.-B. Outbreaks Attributed to Cheese: Differences Between Outbreaks Caused by Unpasteurized and Pasteurized Dairy Products, United States, 19982011. Foodborne Pathogens and Disease, v.11, n.7, 2014. 
KOMATSU, R.-S.; RODRIGUES, M.-A.-M.; LORENO, W.-B.-N.; SANTOS, K.-A. Ocorrência de Staphylococcus coagulase positiva em queijos Minas Frescal produzidos em Uberlândia-MG. Bioscience Journal, v. 26, n. 2, p. 316-321, 2010.

LOMBARDI, E.-C.; CORREIO, M.-T.-N.-P.-R. Qualidade microbiológica do leite e do queijo Minas Frescal processados em duas fábricas de laticínios sob inspeção municipal em Uberlândia MG. Veterinária Notícias, v.20, n. 2, p.71-78, 2014.

LOPES, M.-A.; CARMO, E.-A.; LIMA A.-L.-R.; CARVALHO, F.-M. Análise de rentabilidade de uma empresa com opção de comercialização de queijo ou leite. Arquivo Brasileiro de Medicina Veterinária e Zootecnia, v.58, n.4, 2006.

MARTINS, E.-S.; REIS, N.-E.-V. Determinação de coliformes e Staphylococcus coagulase positiva em queijos Minas Frescal. Revista Brasileira de Tecnologia Agroindustrial, v.6, n.02, p.842-851, 2012.

MELO, F.-D.; DALMINA, K.-A.; PEREIRA, M.-N.; RAMELLA, M.-V.; NETO, A.-T., VAZ, E.-K.; FERRAZ, S.-M. Avaliação da inocuidade e qualidade microbiológica do queijo artesanal serrano e sua relação com as variáveis físico químicas e o período de maturação. Acta Scientiae Veterinariae, v. 41, n. 1, p. 1-7, 2013.

MIYAJI, M.; SOARES, C.-F. Avaliação da gestão do controle de qualidade e segurança alimentar nas micro e pequenas empresas do circuito do queijo. Revista do Instituto de Laticínios Cândido Tostes, v. 57, n.327, p. 120-122, 2002.

MORAES, P.-M., VIÇOSA, G.-N, YAMAZI, A.-K.; ORTOLANI M.-B.-T; NERO, L.-A. Foodborne Pathogens and Microbiological Characteristics of Raw Milk Soft Cheese Produced and on Retail Sale in Brazil. Foodborne Pathogens and Disease. v.6, n.2, p. 245-249, 2009.

PERRY, K.-S.-P. Queijos: Aspectos químicos, bioquímicos e microbiológicos. Química Nova, São Paulo, v. 27, n. 2, p. 293-300, 2004.
PINTO, F.G.S.; SOUZA, M.; SALING, S.; MOURA, A.C. Qualidade microbiológica de queijo Minas Frescal comercializado no município de Santa Helena, PR, Brasil. Arquivo de Instituto de Biologia, v.78, n.2, p.191-198, 2011.

ROCHA, J.-S.; BURITI, F.-C. A.; SAAD, S.-M.-I. Condições de processamento e comercialização de queijo-de-minas Frescal. Arquivo Brasileiro de Medicina Veterinária e Zootecnia, v.58, n.2, p.263-272, 2006.

SENGER, A.-E.-V.; BIZANI, D. Pesquisa de Staphylococcus aureus em queijo Minas Frescal, produzido de forma artesanal e industrial, comercializado na cidade de Canoas/ RS, Brasil. Revista de Ciências Ambientais, v.5, n.2, p. 25-42, 2011.

SOUZA, C.-P. de; PEREIRA, L.-E.-H. de F.; PEREIRA, K.-S. Microbiological Quality and Safety of Minas Frescal Cheese Commercialized Under Federal Inspection in Rio de Janeiro City, RJ, Brazil. Blucher Food Science

Proceedings, v.1, n.1, p. 401-402, 2014.

TORRES-VITELA, M.-R.; MENDOZABERNARDO, M.; CASTRO-ROSAS, J.; GOMEZALDAPA, C.-A.; GARAY-MARTINEZ, L.-E.; NAVARRO-HIDALGO, V.; VILLARRUEL-LÓPEZ, A. Incidence of Salmonella, Listeria monocytogenes, Escherichia coli $\mathrm{O} 157$ : H7, and staphylococcal enterotoxin in two types of Mexican fresh cheeses. Journal of Food Protection, v. 75, n. 1, p. 79-84, 2012.

VALIATTI, T.-B.; SOBRAL, F.-O.-S.; ROMÃO, N.-F.; MALAVASI, N.-V. Avaliação das condições higiênico-sanitárias de queijos tipo Minas Frescal comercializados em feiras no município Ji-Paraná-RO. Revista Científica da Faculdade de Educação e Meio Ambiente, v.6, n.1, p. 59-68, 2015.

VICENTINI, N.-M., CARNEIRO, A.-V.; MENDONÇA, L.-C.; BRITO, M.-A.-V.-P.; BRITO, J.-R.-F. Custo da Adequação de Pequenos Produtores de Queijos aos Requisitos da Legislação do Estado de Minas Gerais. Revista do Instituto de Laticínios Cândido Tostes, v. 68, n. 395, p. 5-14, 2013. 
ZEGARRA, J.-J.-Q.; CAMPBEL, R.-C.; BOTTEON, M.; OLIVEIRA, B.-C.-R.-S; BOTTEON, P.-T.-L.; SOUZA, M.-M. Pesquisa de microrganismos em utensílios, leite e queijos de produção artesanal em unidades de produção familiar no município de Seropédica, Rio de Janeiro. Ciência Animal Brasileira, v. 10, n. 1, p. 312-321, 2009.
ZOCCHE, F.; BASTOS, C.-P.; BASSANI, M.-T.; FRANÇA, R.-C., LIMA, A.-S.-L.; SILVA, W.-P. Estafilococos coagulase positiva em queijos Minas Frescal e minas padrão comercializados em Pelotas, Rio Grande do Sul. Boletim. CEPPA, v. 30, n. 1, p. 119-124, 2012.

Recebido para publicação em 7/10/2016 e aprovado em 15/12/2016. 